\title{
Capstones and Large Projects in Computing Education
}

\author{
MARK SHERRIFF, University of Virginia \\ SARAH HECKMAN, North Carolina State University
}

\begin{abstract}
Capstone and large projects in computing education are used as a vehicle for giving students as close to a "realworld" experience in software development as possible within the constraints of a computing degree program. This special issue presents four articles that focus on empirical research on capstone or other large-scale projects. These articles discuss areas such as project selection, working with external stakeholders, choosing the appropriate development methodology, incorporating creative activities to support student engagement, and learning.
\end{abstract}

CCS Concepts: $\bullet$ Social and professional topics $\rightarrow$ Computer science education; Software engineering education; • Applied computing $\rightarrow$ Collaborative learning;

Additional Key Words and Phrases: Capstone projects, large projects

ACM Reference format:

Mark Sherriff and Sarah Heckman. 2018. Capstones and Large Projects in Computing Education. ACM Trans. Comput. Educ. 18, 2, Article 6 (July 2018), 4 pages.

https://doi.org/10.1145/3229882

\section{INTRODUCTION}

Modern software development is much more than just the sum of the skills that we teach in the classroom. As computing students reach the later stages of their degree programs, there is a desire and a need to give students the opportunity to put all they have learned into practice. In some cases, this opportunity takes the form of internships or co-op programs, where students work in industry to better understand how to apply their skills on a real-world project. However, opportunities in industry are not always available or feasible within a curriculum, and so computing programs look to capstones and other large-scale project courses to give students the experience they need to be successful in the field of software development. Example courses in the ACM/IEEE 2013 Computing Curricula (ACM/IEEE-CS Joint Task Force on Computing Curricula 2013) include project-based coursework and the ABET Computing Accreditation Commission (ABET Computing Accreditation Commission 2017) even requires a major project for computer science programs.

Constructing an effective and meaningful capstone or project-based course that can give students the experience they need is a significant challenge. Instructors must consider how to compress a large project into one or two semesters, how to manage student teams, and how to best motivate students. The body of knowledge regarding how to best structure and deliver capstone and large-scale project courses has been growing significantly in recent years, focusing on topics

Authors' addresses: M. Sherriff, Department of Computer Science, University of Virginia, 85 Engineer's Way, Charlottesville VA 22902; email: sherriff@virginia.edu; S. Heckman, Department of Computer Science, North Carolina State University, 890 Oval Drive, Raleigh NC 27695-8602; email: sarah_heckman@ncsu.edu.

Permission to make digital or hard copies of part or all of this work for personal or classroom use is granted without fee provided that copies are not made or distributed for profit or commercial advantage and that copies bear this notice and the full citation on the first page. Copyrights for third-party components of this work must be honored. For all other uses, contact the Owner/Author.

2018 Copyright is held by the owner/author(s).

1946-6226/2018/07-ART6

https://doi.org/10.1145/3229882 
from course management (O’Leary 2017; Herbert 2018; Neyem et al. 2017; Heckman et al. 2018) to development methodologies (Murphy et al. 2017; Paasivaara et al. 2017) to professional (soft) skills (Carter 2011) to motivating students (Bloomfield et al. 2014; Postner et al. 2018).

In this special issue, four articles were selected that show the range of empirical work being done in capstones and large-scale project-based courses. These articles aim to show best practices in creating, managing, and motivating students as they prepare them for careers in software development.

\section{AREAS OF INTEREST}

The call for papers for this special issue asked for submissions that "effectively present and evaluate any and all aspects regarding the design, implementation, and evaluation of capstone and largescale projects in computing education." Authors were required to submit a long-form abstract as an initial submission for peer review, addressing one or more of the following topic areas:

- How to manage capstones and large projects in the face of rising enrollments

- Capstones to satisfy learning outcomes related to soft skills

- Novel use of projects in computer science education contexts

-Empirical results demonstrating efficacy of project and capstone courses

- Software engineering skills for large-scale projects

-Industrial sponsored projects and working with industrial partners

- Long running or multi-semester projects

- Multi-disciplinary projects and working with other disciplines

- Legal and ethical issues

- Handling interpersonal complexities for project teams

- Evaluating contribution and participation in team projects

-Working with not-for-profit organizations

-Contributing to open source projects

Thirty-five abstracts were submitted from all over the world, including Australia, Brazil, Canada, Germany, Great Britain, Finland, France, Israel, Italy, Saudi Arabia, Spain, South Africa, and the United States. The editors and reviewers selected 12 abstracts from this set, representing a broad cross section of topics and research areas, to move to the full article submission phase.

The final articles presented in this special issue were reviewed by the editors, external reviewers, and by the other submitting authors.

\section{ARTICLES IN THIS ISSUE}

The four articles selected cover a wide range of the topics listed above. A synopsis of each article is presented below.

\subsection{Using Free/Open Source Software in Large-Scale Projects}

Free and open source software (FOSS) is a resource for educators seeking a more complex software development project experience in their classrooms. However, adoption of FOSS or humanitarian free and open source software (HFOSS) in a project course can be complex. In "A Multi-Institutional Perspective on H/FOSS Projects in the Computing Curriculum," Braught et al. describe five models for using H/FOSS projects in undergraduate coursework to support exposure to large software development projects.

In addition to describing how H/FOSS was integrated into specific courses, the authors identify five themes for consideration when integrating H/FOSS projects at other institutions: integration into courses and curricula; selection of projects; teaming and engagement with the H/FOSS 
community; design and assessment of student assignments; and how to identify resources to help with integration of H/FOSS into a course/curriculum. Challenges and opportunities are discussed so that others can successfully adopt and evaluate H/FOSS offerings in their own classes.

\subsection{Working with External Stakeholders}

Project and capstone courses will frequently engage external, typically industrial, stakeholders from guest lecturers through product owners. In "Working with External Stakeholders," Steghöfer et al. present a model for the involvement of external stakeholders in project-based courses. The model, created and validated over six iterations by a "guild of teachers," incorporates the context of the project course, driving questions about the collaboration to build an action plan, and a reflection on the execution to drive further innovation and improvement. The experience of stakeholder engagement is viewed through six lenses that consider the instructor, student, and stakeholder.

The authors demonstrate the efficacy of their model through a retrospective analysis of eight courses at four institutions from three countries. Using the model, the authors identify seven risk themes and suggest mitigation strategies that will be beneficial for educators planning to incorporate projects from external stakeholders into their courses. Additionally, the authors demonstrate the use of their model on the construction of a new course. Two appendices provide details for application of the model in other contexts.

\subsection{Deciding on a Software Development Methodology}

A question that instructors of software engineering and project-based courses often have is what development methodology to use with their students. Many courses use some variation of an agile methodology, but even then there are numerous options to consider. In "A Scalable Methodology to Guide Student Teams Executing Computing Projects," Saltz and Heckman consider three different software development methodologies and examine their effects on student teams and the associated instructor workload. Scrum, Kanban, and CRISP are compared to a control group in which no structured methodology was given to the students.

To measure the effects these development methodologies had on the teams, Saltz and Heckman present a theoretical model for comparing team performance between the different experiment groups based on existing literature. Their model considers solution quality, user perceptions of the solution, and team satisfaction. In their mixed-methods study, Saltz and Heckman found particular aspects of the different methodologies that had overall positive effects on the student experience and consider future work for how they might be combined into a process specifically for student projects.

\subsection{Adding Theater to Project Demonstrations}

When teaching students about software development with external customers for the first time, it can often be difficult to transition students from thinking about their project as something for a class into a piece of software that will be used by real users. In "Software Theater Teaching Demo-Oriented Prototyping," Krusche, Dzvonyar, Xu, and Bruegge add a new layer to capstone courses by introducing aspects of theater to scenario-based design and project demonstration. Students create "screenplays" based on high-level scenarios and personas of potential users. These screenplays are iterated on by teams as they try to best understand the requirements of the system they are creating and how to communicate their designs to their customer.

Krusche et al. describe two courses in which they used their software theater methodology. In both cases, students reported that the added level of creativity that the technique provided not only helped them better understand the requirements, but also simply made the process more 
fun and engaging overall. The authors provide several best practices they have learned from the refinement of their methodology so that other instructors can build on what they have learned.

\section{ACKNOWLEDGMENTS}

We would like to acknowledge the contributions of several external reviewers: Lina Battestilli, Grant Braught, Dora Dzvonyar, Marko van Eekelen, David Goldschmidt, Regina Hebig, Steven Huss-Lederman, Mukkai Krishnamoorthy, Stephan Krusche, Shreya Kumar, Grischa Liebel, Patricia López Martínez, John MacCormick, Julio Medina, Vreda Pieterse, Jeffrey Saltz, Pablo Snchez, Jan-Phillipp Steghfer, Wesley Turner, Luther Tychonievich, Alfonso de la Vega, Charles Wallace, and Han Xu. We would also like to thank the editorial staff at the ACM and TOCE for their guidance in creating this special issue.

\section{REFERENCES}

ABET Computing Accreditation Commission. 2017. Criteria for Accrediting Computing Programs, Version 2.0. Technical Report. ABET. Retrieved from http://www.abet.org/accreditation/accreditation-criteria/cac-18-19/.

ACM/IEEE-CS Joint Task Force on Computing Curricula. 2013. Computer Science Curricula 2013. Technical Report. ACM Press and IEEE Computer Society Press. DOI : http://dx.doi.org/10.1145/2534860

Aaron Bloomfield, Mark Sherriff, and Kara Williams. 2014. A service learning practicum capstone. In Proceedings of the 45th ACM Technical Symposium on Computer Science Education (SIGCSE'14). ACM, New York, NY, 265-270. DOI : http:// dx.doi.org/10.1145/2538862.2538974

Lori Carter. 2011. Ideas for adding soft skills education to service learning and capstone courses for computer science students. In Proceedings of the 42nd ACM Technical Symposium on Computer Science Education (SIGCSE'11). ACM, New York, NY, 517-522. DOI : http://dx.doi.org/10.1145/1953163.1953312

Sarah Heckman, Kathryn T. Stolee, and Christopher Parnin. 2018. 10+ years of teaching software engineering with itrust: the good, the bad, and the ugly. In Proceedings of the 40th International Conference on Software Engineering: Software Engineering Education and Training (ICSE-SEET'18). ACM, New York, NY, USA, 1-4. DOI : https://doi.org/10.1145/3183377. 3183393

Nicole Herbert. 2018. Reflections on 17 years of ICT capstone project coordination: Effective strategies for managing clients, teams and assessment. In Proceedings of the 49th ACM Technical Symposium on Computer Science Education (SIGCSE'18). ACM, New York, NY, 215-220. DOI : http://dx.doi.org/10.1145/3159450.3159584

Christian Murphy, Swapneel Sheth, and Sydney Morton. 2017. A two-course sequence of real projects for real customers. In Proceedings of the 2017 ACM SIGCSE Technical Symposium on Computer Science Education (SIGCSE'17). ACM, New York, NY, 417-422. DOI : http://dx.doi.org/10.1145/3017680.3017742

Andres Neyem, Juan Diaz-Mosquera, Jorge Munoz-Gama, and Jaime Navon. 2017. Understanding student interactions in capstone courses to improve learning experiences. In Proceedings of the 2017 ACM SIGCSE Technical Symposium on Computer Science Education (SIGCSE'17). ACM, New York, NY, 423-428. DOI : http://dx.doi.org/10.1145/3017680.3017716

Mike O'Leary. 2017. Innovative pedagogical approaches to a capstone laboratory course in cyber operations. In Proceedings of the 2017 ACM SIGCSE Technical Symposium on Computer Science Education (SIGCSE'17). ACM, New York, NY, 429-434. DOI : http://dx.doi.org/10.1145/3017680.3017720

Maria Paasivaara, Jari Vanhanen, Ville T. Heikkilä, Casper Lassenius, Juha Itkonen, and Eero Laukkanen. 2017. Do high and low performing student teams use scrum differently in capstone projects? In Proceedings of the 39th International Conference on Software Engineering: Software Engineering and Education Track (ICSE-SEET'17). IEEE Press, 146-149. DOI : http://dx.doi.org/10.1109/ICSE-SEET.2017.22

Lori Postner, Heidi J. C. Ellis, and Gregory W. Hislop. 2018. A survey of instructors' experiences supporting student learning using HFOSS projects. In Proceedings of the 49th ACM Technical Symposium on Computer Science Education (SIGCSE'18). ACM, New York, NY, 203-208. DOI : http://dx.doi.org/10.1145/3159450.3159524

Received May 2018; revised June 2018; accepted June 2018 